$6-30-2020$

\title{
Evidence review: Promoting adolescent girls' health and well- being in low-resource settings in the era of COVID-19
}

\author{
Sarah Blake \\ Population Council \\ Miriam Temin \\ Population Council \\ Adolescent Girls Investment Plan (AGIP) Evidence Subcommittee
}

Follow this and additional works at: https://knowledgecommons.popcouncil.org/departments_sbsr-pgy

Part of the Social and Behavioral Sciences Commons

How does access to this work benefit you? Let us know!

\section{Recommended Citation}

Blake, Sarah, Miriam Temin, on behalf of the Adolescent Girls Investment Plan (AGIP) Evidence Subcommittee. 2020. "Evidence review: Promoting adolescent girls' health and well-being in low-resource settings in the era of COVID-19," Study description. New York: Population Council. 
Evidence Review: Promoting Adolescent Girls' Health and Well-Being in Low-Resource Settings in the Era of COVID-19 1

Study Description

June 30,2020

Authors: Sarah C. Blake ${ }^{1}$ and Miriam Temin ${ }^{1}$, on behalf of Adolescent Girls Investment Plan (AGIP) Evidence Subcommittee

Affiliations:

1. Population Council

\section{Corresponding authors:}

Sarah C. Blake, MPH, MSc

Staff Associate, Poverty, Gender, and Youth Program

sblake@popcouncil.org

Miriam Temin, MSc

Project Director \& Associate II, Poverty, Gender, and Youth Program

+1 212 339-0500

mtemin@popcouncil.org

\section{POPULATION COUNCIL}

IDEAS. EVIDENCE. IMPACT.

One Dag Hammarskjold Plaza

New York, NY 10017

www.popcouncil.org

This evidence review is conducted under the auspices of the Adolescent Girls Investment Plan (AGIP). Under AGIP, 11 partners from civil society and knowledge and research institutions are collaborating to galvanize support, engagement and investment from governments, foundations and other stakeholders to bring to life an approach that will secure the rights and wellbeing of all adolescent girls. Partners include: Plan International, Girls Not Brides, Women Deliver, the International Planned Parenthood Federation (IPPF), The Population Council, the Overseas Development Institute (ODI), the International Center for Research on Women (ICRW), Bill \& Melinda Gates Foundation, Ford Foundation, Malala Fund and FRIDA. The Evidence Subcommittee includes ODI; Plan International; ICRW, IPPF, Malala Fund, and the Ford Foundation.

\section{Description:}

Adolescent girls are among the groups intended to benefit from measures governments enact to control COVID-19, such as travel restrictions and business and school closures. However, given the

\footnotetext{
${ }^{1}$ This document is evolving due to the nature of the COVID-19 response and will be updated as needed.
} 
dual disadvantage adolescent girls face due to age and gender, even approaches that effectively reduce the threat of COVID-19 transmission may exacerbate other threats to their health, safety, and well-being. In response, governments, multilateral agencies, and non-governmental organizations have moved to address these risks, though evidence to support investment decision-making is limited. Clarity on the type, degree, and strength of the evidence in support of interventions that promote adolescent girls' health and well-being is urgently needed. We are conducting an evidence review to meet this challenge. Based on the findings of a structured literature search of published and selected grey literature sources, we will map the current scope of evidence on relevant interventions in low- and middle-income countries. Based on this mapping, we will identify the implications for interventions and research on girls' health and well-being as the crisis evolves across diverse contexts.

\section{Background}

The COVID-19 pandemic is both a global health emergency and a set of overlapping social and economic crises unfolding at different paces, and with different impacts, over time and across contexts. The content and timing of government responses, existing structural conditions, and community and individual practices alike mean that both the severity of COVID-19-specific risks and secondary dimensions of the crisis vary over time and place. As governments enact COVID-19 control measures such as travel restrictions, business and school closures, even approaches that are effective in reducing the threat of COVID-19 transmission may also exacerbate other threats to health, safety, and wellbeing. 'In response, multilateral agencies, governments, and non-governmental organizations (NGOs) have expanded social protection measures, such as cash transfers, food distribution and nutrition assistance; introduced computer, mobile phone, television and radio-based alternatives to schooling; and expanded measures such as hotlines that offer support for gender-based violence survivors or advice on other health concerns. ${ }^{\text {ii,iii }}$

While adolescent girls are among the groups intended to benefit from alternative services and risk mitigation efforts, this is no guarantee that they have sufficient support. Children, and girls, in particular, are often overlooked in efforts to plan for emergencies. ${ }^{\text {iv }}$ Pre-pandemic, many girl-serving programs and services were already under-resourced, and the pandemic may exacerbate this situation as critical interventions are de-prioritized or suspended. vivi At the same time, woman-led civil society organizations, including those representing girls and their interests receive limited funding, constraining their ability to hold decision-makers accountable. ${ }^{\text {vii }}$ Finally, measures introduced under the guise of a response to COVID-19 may also carry destructive ideological dimensions. For example, many countries have misclassified reproductive health care as "non-essential," imposing new barriers to service access. ${ }^{\text {viii }}$

Recent research, including qualitative studies from settings such as rural Ethiopia and among refugee communities in Lebanon, suggest that girls are facing an emerging set of common effects. For example, across settings, girls describe increased burdens of unpaid care work, new levels of food insecurity, and new feelings of distress, fear, and anxiety. ${ }^{i x, x}$ To note, even within the same communities, girls may face different realities. A recent survey of girls in five districts in Bangladesh found that larger proportions of girls 16 and older reported increased burdens of household work or caregiving responsibilities than 
younger girls; and more married girls reported recent experiences of household violence than unmarried peers. ${ }^{\text {i }}$ Moreover, girls' experiences are not solely marked by heightened risks or vulnerabilities that require interventions; they are also responding to the pandemic: studies suggest that older girls, in particular, are contributing to efforts to educate their peers or community members. .ii $^{\text {xi }}$ There is little question that the COVID-19 crisis will reshape girls' lives in critical and lasting ways as the crisis evolves. Clarity on the type, degree, and strength of the evidence in support of interventions that promote adolescent girls' health and wellbeing in LMIC is urgently needed. We are conducting an evidence review to meet this challenge. The review of evidence and its implications will take account of the unique nature of the adolescent life phase and girls' heterogeneity as it is shaped by age, household economic status, the community or country where they live, their ethnicity, nationality, disability, marital status or sexual orientation. In the course of reviewing evidence, we will incorporate a focus on contexts within LMIC where poverty, weak social infrastructure, or exclusion from official government services contribute to heightened risks and constrained opportunities for girls, even in periods of apparent stability.

Our evidence review will be informed by:

- A conceptual framework that synthesizes evidence on girl-specific implications of the COVID-19 crisis based on emerging findings and evidence from past crises ${ }^{\text {xiii; }}$

- Consultations with representatives of AGIP member organizations;

- A review of global guidance and initial reporting from multilateral agencies on the gender and age-related implications of the COVID-19 crisis for girls living in LMICs; and

- Findings from preliminary reports of primary research with adolescent girls in LMICs conducted by the Population Council and the Overseas Development Institute.

\section{Objectives:}

We will pursue the following objectives as we assess the state of evidence documenting interventions that hold promise for addressing the distinct risks that the COVID-19 crisis poses for girls:

1. Identify high-potential intervention approaches that contribute to reducing girls' risks of contracting COVID-19; including interventions intended to promote individual girls' uptake of protective behaviors such as handwashing; and interventions such as cash assistance, food and supply distribution that enable participation in social distancing and household quarantines.

2. Identify interventions that hold promise to mitigate the secondary effects of COVID-19 on girls in contexts where recurrent outbreaks and control measures disrupt health and social services, schooling, or community-based programs likely. These include measures that address risks such as household and community violence, sexual and reproductive health-related risks, social isolation, mental health problems, and de-learning.

3. Identify intervention approaches that hold promise for "building back better," with and for adolescent girls in the long-term recovery period, once disease transmission has been controlled or stabilized globally but economic or social effects remain. These include measures that address long-term effects, such as lost schooling and training opportunities and prolonged economic insecurity; and those 
that relate to critical elements of physical or social infrastructure, such as information and communication technologies, water and sanitation, and transportation.

4. Identify priority evidence gaps in areas such as: what kinds of interventions are evaluated; what outcomes are prioritized; which sub-populations of girls are included; and what forms of instability or exclusion are accounted for in intervention design or evaluations.

\section{Methodology:}

\section{Search Strategy}

a. General search: We will conduct a broad literature search, using key words to represent intervention descriptors, in combination with potential groupings of the adolescent girl population. (See Annex A. for proposed search terms). We will conduct this search on the following databases: PubMed, JSTOR, and Google Scholar.

b. Purposive in-depth search: We will conduct a hand search of grey literature documenting evaluations of girl-serving interventions based on citations from peer-reviewed articles, and a review of key institutional databases, including the Population Council's GIRL Center, and websites for the Overseas Development Institute, the International Center for Research on Women, and Girls Not Brides, Youth Power, and 3IE.

\section{Identification of studies for inclusion}

We will review titles and abstracts of articles to select studies for inclusion in the analysis, based on the following criteria:

\section{○ Inclusion:}

- Data collected and interventions conducted in a national or subnational LMIC context affected by ongoing crisis or instability, such as:

- Complex humanitarian emergencies (conflict and displacement; largescale natural disasters)

- Drought, flooding, or potential food shortages

- Economic or financial crisis

- Domestic civil unrest or political instability

- Informal settlements, or camp setting

- Peer-reviewed articles based on primary or secondary analysis of quantitative, and/or qualitative data, including systematic reviews and meta-analyses

- Research reports from grey literature that meet standards of rigorous research, such as clear descriptions of research questions, methods, sample size and sampling approach, and description of data collection and analysis.

- Measures effects of a formal intervention, i.e.: policy, service delivery, community programming, messaging campaign, or community-led initiative with clear intended girl-level outcomes.

- Includes age and sex disaggregated data and measurement of outcomes among adolescent girls aged 10-19. 
- Published since 2005, in English.

\section{○ Exclusion:}

- Grey or peer-reviewed published literature lacking research questions, theory or hypothesis to apply to evaluation, description and justification of sampling approach, or methods used in data collection and analysis

- Studies that do not evaluate an intervention

- Evaluation of an intervention that does not:

- measure girl-level outcomes

- disaggregate data by sex

- disaggregate female-identified participants by, at least, a division between adolescent and adult age brackets.

\section{Data Extraction}

Once we have identified articles that fit the inclusion criteria, we will record details such as title, source, authorship, and year of publication. We will then organize according to the below PICOS framework: ${ }^{\text {iv }}$

\section{a. Description of population:}

- Ages of girls included

- Whether girls are included in a broader study population (e.g. also including boys or young women) or treated as a primary population of interest

- Any additional socio-demographic descriptors reported for participants, such as marital status, school-going, disability, or migrant or refugee status

b. Intervention and Context: We will group evaluations according to categories of interventions and the contexts in which they were implemented, noting geographic region; community types (e.g. urban vs. rural); and form or source of instability or crisis (for example: complex humanitarian emergency, economic crisis, political crisis).

c. Intended outcome(s) of intervention. We will also organize evaluations according to their intended girl-level outcomes. Interventions with multiple outcomes will be assigned to multiple groups or categories. For example, interventions that intend to improve girls' health and educational outcomes, will be assigned to both "health" and "education."

c. Study Type: We will also organize sources according to the type of research methods used. After specifying whether they employ a meta-analysis or systematic review; quantitative methods; or qualitative methods, we will also group by specific types of methods used.

\section{Assessment of Study Quality}

We will evaluate the included studies' quality and risk of bias based on clarity and rigor of research methods, by identifying and assessing:

- Sample size justification

- Clarity and appropriateness of research method choice 
Ideas. Evidence. Impact.

- Clarity and justification for sociodemographic profiles of participants

- Degree of disaggregation of participants

- Reporting of missing data

- Discussion of limitations

- Clarity and appropriateness of outcomes measured

\section{Synthesis \& Map Creation}

We will create a visual "map" reflecting the organization of the quality of research methods; and categories of interventions and outcomes. This will order sources according to their fit with each of the first three aforementioned objectives. We will also synthesize findings in a narrative report and a brief that reflect the state of the evidence as presented in the map, priority gaps in evidence, and the implications for research, policy, and practice. 


\section{Annex A. Draft Search Terms}

\begin{tabular}{|c|c|c|}
\hline Intervention Descriptors & \multirow[t]{18}{*}{ [AND] } & Populations \\
\hline $\begin{array}{l}\text { adolescent-friendly health; } \\
\text { adolescent and youth-friendly } \\
\text { health services }\end{array}$ & & Adolescent, teenager, teen-aged \\
\hline $\begin{array}{l}\text { cash transfer; conditional cash } \\
\text { transfer; unconditional cash } \\
\text { transfer; asset transfer; labeled } \\
\text { cash transfer }\end{array}$ & & Adolescent girls \\
\hline $\begin{array}{l}\text { child-friendly space, girl-friendly } \\
\text { space }\end{array}$ & & Mar \\
\hline community health worker & & Unmarried girls \\
\hline community-based provision & & Very young adolescents \\
\hline $\begin{array}{l}\text { community engagement, } \\
\text { community mobilization, } \\
\text { community sensitization }\end{array}$ & & Disability, girls living with disability \\
\hline $\begin{array}{l}\text { comprehensive sexuality } \\
\text { education, sexuality education, } \\
\text { family life education }\end{array}$ & & $\begin{array}{l}\text { LGBTQ youth, sexual and gender minority } \\
\text { youth }\end{array}$ \\
\hline Counseling & & \\
\hline financial literacy & & \\
\hline life skills & & \\
\hline livelihoods & & \\
\hline mass media & & \\
\hline $\begin{array}{l}\text { menstrual hygiene } \\
\text { management, MHM }\end{array}$ & & \\
\hline mhealth, telehealth & & \\
\hline mobile phone, social media & & \\
\hline nonformal education & & \\
\hline $\begin{array}{l}\text { nutrition assistance, nutrition } \\
\text { education, nutrition } \\
\text { supplementation }\end{array}$ & & \\
\hline
\end{tabular}




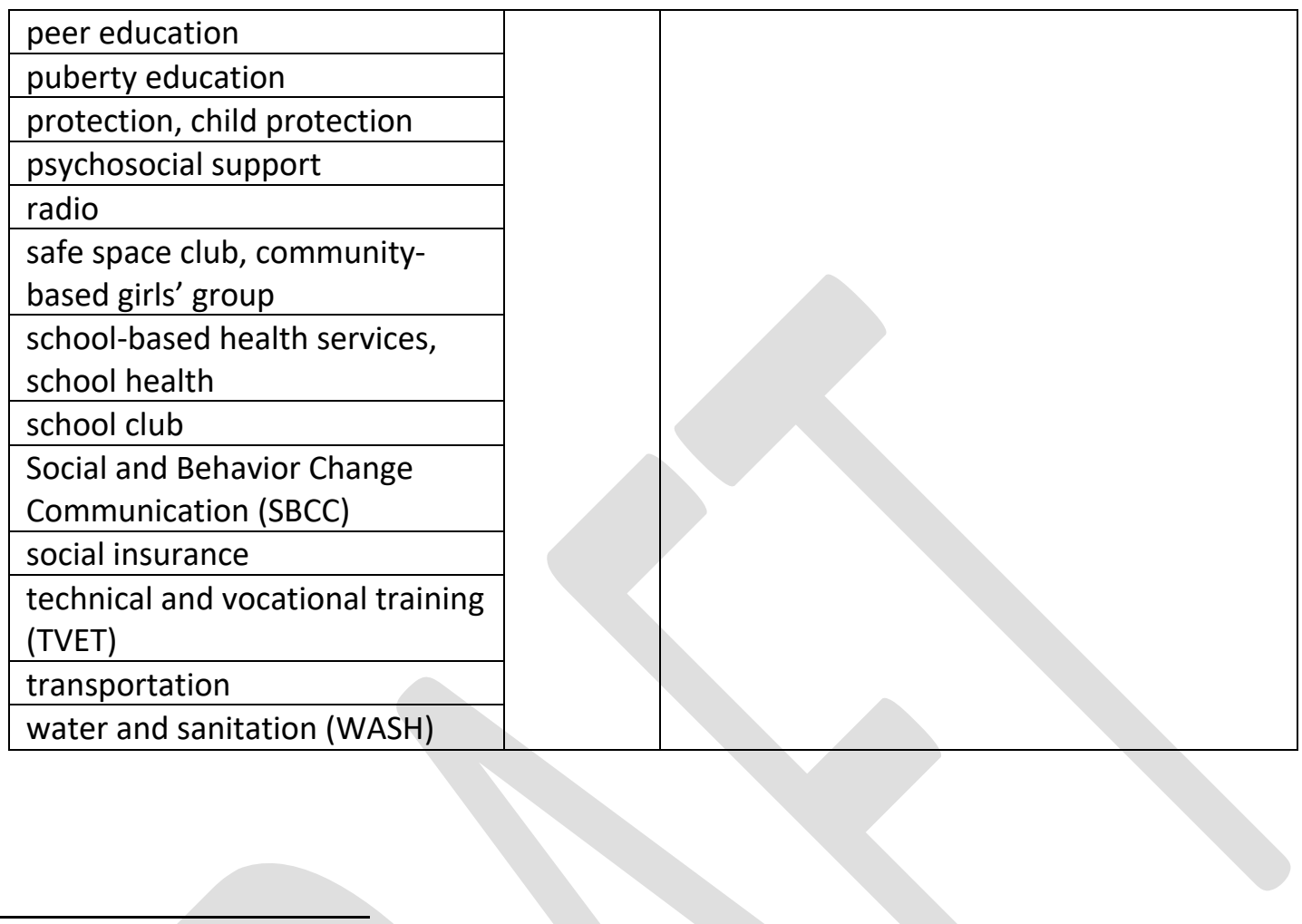

i UNFPA (2020). "Impact of the COVID-19 Pandemic on Family Planning and Ending Gender-based Violence, Female Genital Mutilation and Child Marriage" Interim Technical Note. https://www.unfpa.org/sites/default/files/resource-pdf/COVID19 impact brief for UNFPA 24 April 2020 1.pdf

ii Gentilini, U., Almenfi, M., Orton, I. and P. Dale (2020). "Social Protection and Jobs Responses to COVID-19: A Real-Time Review of Country Measures (May 8, 2020)." COVID-19 Living Paper. Washington, DC: World Bank https://documents.worldbank.org/en/publication/documents-reports/documentdetail/448321588971503966/socialprotection-and-jobs-responses-to-covid-19-a-real-time-review-of-country-measures-may-8-2020

iii Tirivayi, N., Richardson, D., Gavilovic, M., et al. (2020). “A rapid review of economic policy and social protection responses to health and economic crises and their effects on children Lessons for the COVID-19 pandemic response. Innocenti Working Paper 2020-2. UNICEF. https://www.unicef-irc.org/publications/pdf/WP2020-02.pdf

iv Tirivayi, N., Richardson, D., Gavilovic, M., et al. (2020). “A rapid review of economic policy and social protection responses to health and economic crises and their effects on children Lessons for the COVID-19 pandemic response. Innocenti Working Paper 2020-2. UNICEF. https://www.unicef-irc.org/publications/pdf/WP2020-02.pdf

$\checkmark$ IRC and VOICE (2019). Where is the Money? How the Humanitarian System is Failing in its Commitments to End Violence Against Women and Girls. https://www.rescue.org/sites/default/files/document/3854/whereisthemoneyfinalfinal.pdf vi Tirivayi, et al., (2020).

vii OECD. (2016). Donor Support to Southern Women's Rights Organisations. OECD DAC Network on Gender Equality (GENDERNET)

viii IPPF (2020). COVID-19 Pandemic Cuts Access to Sexual and Reproductive Healthcare for Women Around the World. https://www.ippf.org/news/covid-19-pandemic-cuts-access-sexual-and-reproductive-healthcare-women-around-world ix Youssef, S., Jones, N., Małachowska, A. with Saleh, M. (2020) 'Listening to young people's voices under covid-19. Double crisis in Lebanon: effects of a pandemic and economic crisis on Lebanon's most vulnerable adolescents.' Policy brief. London: Gender and Adolescence: Global Evidence.

x Jones, N., Gebeyehu, Y., Gezahegne, K, lyasu, A., Tlahun, K., Workneh, F., and Yadete, W. (2020), 'Listening to young people's voices under covid-19. Exploring adolescents' experiences and priorities in Ethiopia under covid-19.' Policy brief. London: Gender and Adolescence: Global Evidence.

xi Population Council. 2020. "Bangladesh: COVID-19 Knowledge, Attitudes, Practices \& Needs: Responses from the first round of data collection among adolescent girls in five districts." 
Ideas. Evidence. Impact.

xii Hamad, S., Abu Hamra, E., Diab, R., Abu Hamad, B., Jones, N. and Małachowska, A. (2020) 'Listening to young people's voices under covid-19. Exploring the impacts of covid-19 on adolescents in the Gaza Strip.' Policy brief. London: Gender and Adolescence: Global Evidence.

xiii Can be accessed in future on the AGIP website (forthcoming, 2020).

xiv Methley, A.M., Campbell, S., Chew-Graham, C. (2014). PICO, PICOS and SPIDER: a comparison study of specificity and sensitivity in three search tools for qualitative systematic reviews. BMC Health Serv Res 14, 579.

https://doi.org/10.1186/s12913-014-0579-0

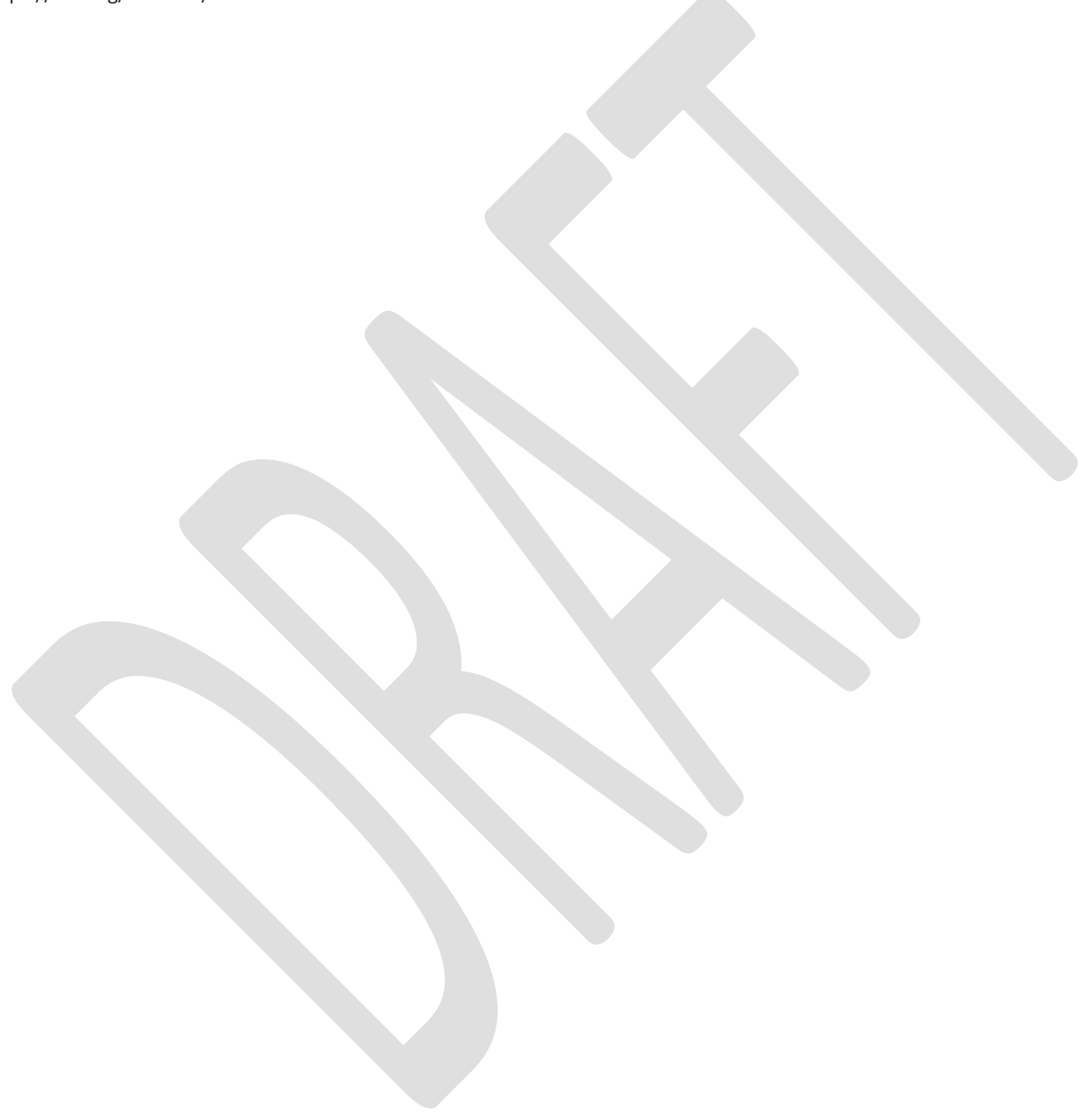

